\title{
A edição de livros didáticos de línguas estrangeiras destinados ao PNLD: algumas considerações
}

\author{
Sandra Possas \\ Universidade de Londres \\ Roberta Amendola \\ USP
}

\begin{abstract}
Resumo
Este artigo tem por objetivo apresentar alguns aspectos relacionados à edição de livros didáticos (LDs) de línguas estrangeiras destinados ao Programa Nacional do Livro Didático (PNLD). Para tanto, partimos das funções e limitações dos LDs propostas por Choppin (2001), pelo edital referente ao PNLD 2012 (BRASIL, 2012) e por Costa (2014). Abordamos tópicos como as especificações para produção dos materiais, o componente de inovação no setor editorial e o impacto do PNLD de Línguas Estrangeiras Modernas para os envolvidos e afetados pelo Programa.
\end{abstract}

Palavras-chave: edição; livros didáticos; línguas estrangeiras; PNLD.

\begin{abstract}
This article presents some aspects of the editing of foreign language textbooks submitted to the Programa Nacional do Livro Didático (PNLD).

The analysis is based on the textbook functions and limitations as suggested by the guidelines for the PNLD 2012 (BRASIL, 2012), and by Costa (2014) and Choppin (2001). We cover topics such as the specifications for the production of materials, the innovation component in the publishing industry and the impact that the PNLD for Foreign Languages has on those involved in and affected by the Program.
\end{abstract}

Keywords: editing; textbooks; foreign languages; PNLD.

\section{INTRODUCTION}

Em $2011^{1}$ o Governo Federal inseriu Línguas Estrangeiras Modernas (LEM) inglês e espanhol - no Programa Nacional do Livro Didático (PNLD), por meio do qual adquire livros impressos e conteúdos digitais para mais de 30 milhões de alunos de escolas

\footnotetext{
1 Neste texto utilizamos os nomes oficiais dos programas, que correspondem aos anos de utilização dos materiais. No caso em questão, trata-se do PNLD 2011.
} 
públicas $^{2}$. Na primeira edição foram contemplados os estudantes de Ensino Fundamental e, no ano seguinte, os de Ensino Médio. Desde então, as LEM seguem o cronograma de avaliação e compra de livros didáticos (LDs) para o PNLD.

Tal iniciativa alavancou o mercado editorial de inglês e espanhol ao gerar uma demanda muito significativa devido ao volume de livros a serem adquiridos. O setor, em contínuo crescimento no segmento de escolas privadas regulares, teve que se especializar e realizar investimentos para atender a esse novo cliente e às especificidades dos materiais por ele adquiridos.

Posicionamo-nos neste texto a partir da nossa experiência como editoras e executivas editoriais de línguas estrangeiras que vivenciaram todas as edições do programa. Compõem essa bagagem também nossa formação acadêmica e nossas impressões enquanto cidadãs. Embora tais vivências advindas da prática não se embasem em referenciais teóricos, acreditamos que elas podem contribuir para reflexões sobre um dos eixos da Educação em geral pouco conhecido: o da produção de materiais didáticos ${ }^{3}$.

Nas próximas linhas trataremos dos desafios da edição de coleções a serem inscritas no PNLD. No entanto, antes de adentrarmos no tema, é fundamental estabelecer o que se entende por livro didático, quais as suas capacidades e limitações, bem como esclarecer qual é (ou deveria ser) o seu papel no processo de ensino e aprendizagem.

\section{O LIVRO DIDÁTICO}

Para definir o livro didático como produto social e abordar alguns dos diversos aspectos relacionados a ele, trazemos as contribuições de Alain Choppin (2001, p. 214215), historiador francês das edições didáticas:

É necessário partir de uma simples, mas fundamental constatação: todo livro didático está histórica e geograficamente determinado; é o produto de um grupo social e de uma época determinada. Como os livros didáticos são, como vimos, objetos complexos, seus traços característicos e sua evolução histórica são o resultado de um grande número de parâmetros

\footnotetext{
${ }^{2}$ Dado referente ao PNLD 2016, incluindo Ensino Fundamental, Médio, Educação de Jovens e Adultos e Programa Brasil Alfabetizado em entidades parceiras do Governo, segundo o Fundo Nacional de Desenvolvimento da Educação. Disponível em <http://www.fnde.gov.br/programas/livro-didatico/livrodidatico-dados-estatisticos>. Acesso em: 11 jun. 2016.

${ }^{3}$ Há pouquíssimos estudos acadêmicos sobre a produção de livros didáticos e suas etapas; a maioria das pesquisas se voltam para a sua avaliação. Entre os estudos sobre edição de LD destacam-se TEIXEIRA 2012 e MUNAKATA 1997.
} 
cuja natureza é diferente, e que implicam interlocutores diversos, cujas interações são também complexas. Podemos estabelecer uma lista breve, mas não limitativa: didático

- o estatuto e as funções conjuntamente destinadas ao livro

- vetor ideológico e cultural (aspecto político, tanto no sentido restrito quanto no amplo)

- depositário de um conteúdo disciplinar (aspecto programático)

- ferramenta pedagógica (aspecto instrumental).

- limitações de tipo regulamentar (elaboração, produção, escolha, difusão, financiamento etc.).

- limitações de tipo tecnológico (papel, técnicas de impressão, de reprodução etc.).

- limitações de tipo financeiro (custos de produção e de difusão).

- limitações de tipo comercial (estado da concorrência).

- a natureza do ou dos público(s) indicado(s)

- alunos (meninos e meninas, ou dos dois sexos indiferentemente)

- professores

- pais

- outros

- uma combinação de todos eles.

- individual

- o tipo de utilização

- coletiva

- em classe

- em casa

- no Centro de Documentação e de Informação (CDI) (época recente).

- características do público ao que se ensina

- homogêneo

- heterogêneo.

- objetivos (explícitos ou implícitos) atribuídos à formação

- simples memorização dos conteúdos ou aquisição de mecanismos

- desenvolvimento do espírito crítico e conquista da autonomia.

- métodos pedagógico [sic] postos em prática.

- desenvolvimento de outras ferramentas pedagógicas

- em paralelo?

- complementares?.

- critérios explícitos e implícitos de escolha e suas modalidades.

- nível de formação dos docentes

- seu conhecimento dos conteúdos disciplinares

- sua aptidão para utilizar as diferentes ferramentas pedagógicas das que pode dispor.

- etcétera. ${ }^{4}$ (Tradução livre nossa.)

${ }^{4}$ Texto original: Es necesario partir de una simple pero fundamental constatación: todo manual está histórica y geográficamente determinado; es el producto de un grupo social y de una época determinada. Como los manuales son, lo hemos visto, objetos complejos, sus rasgos característicos y su evolución histórica son el resultado de un gran número de parámetros cuya naturaleza es diferente, y que implican interlocutores diversos, cuyas interacciones son así mismo complejas. Podemos establecer una lista breve, pero no limitativa:

- el estatuto y las funciones conjuntamente destinados al manual

- vector ideológico y cultural (aspecto político, tanto en sentido estricto como en el amplio) 
Assim, o LD é uma ferramenta pedagógica portadora dos conteúdos programáticos e dos valores de uma sociedade. Ele possui diversas limitações e está condicionado ao público a que se destina, aos objetivos de ensino e aprendizagem, ao uso que se faz dele e à formação de professores. Suporte limitado para a sala de aula, carrega em si o peso de diversas funções e expectativas, muitas das quais não lhe competem.

Nesse sentido, tal definição está alinhada à assumida pelo Ministério da Educação (MEC), conforme exposto no edital para o PNLD 2012:

... [o livro didático é] um objeto de cultura, produzido conforme um quadro de fundamentos teórico-metodológicos e destinado a orientar as atividades do ensino escolar. Reúne, portanto, a indicação de um caminho e a explicitação das pistas de como atingir as metas pretendidas.

- depositario de un contenido disciplinario (aspecto programático)

- herramienta pedagógica (aspecto instrumental).

- limitaciones de tipo reglamentario (elaboración, producción, elección, difusión, financiación, etc.).

- limitaciones de tipo tecnológico (papel, técnicas de impresión, de reproducción, etc.).

- limitaciones de tipo financiero (costes de producción y de difusión).

- limitaciones de tipo comercial (estado de la competencia).

- la naturaleza del o de los público(s) apuntado(s)

- alumnos (niños o niñas, o de los dos sexos indiferentemente)

- maestros

- padres

- otros

- una combinación de todos ellos.

- el tipo de utilización

- individual

- colectiva

- en clase

- en casa

- en el Centro de Documentación y de Información (CDI) (época reciente).

- características del público al que se enseña

- homogéneo

- heterogéneo.

- objetivos (explícitos o implícitos) asignados a la formación

- simple memorización de los contenidos o adquisición de mecanismos

- desarrollo del espíritu crítico y conquista de la autonomía.

- métodos pedagógico [sic] puestos en práctica.

- desarrollo de otras herramientas pedagógicas

- ¿en competencia?

- ¿complementarios?.

- criterios explícitos e implícitos de elección y sus modalidades.

- nivel de formación de los docentes

- su conocimiento de los contenidos disciplinarios

- su aptitud para utilizar las diferentes herramientas pedagógicas de las que pueden disponer.

- etcétera. 
Especificamente, em relação ao trabalho com as linguagens, o livro didático deve 'abrir' o interesse do aluno para questões bem mais amplas e relevantes socialmente. Deve favorecer a convivência do aluno com diferentes representações de linguagem, com diferentes modalidades de tipos e gêneros de textos, de épocas, regiões, funções, registros diversificados. Deve favorecer a formação de um leitor crítico e interativo, capaz de ultrapassar a mera decodificação de sinais explícitos. Deve desenvolver nos alunos competências em atividades de expressão oral e escrita, com diferentes propósitos comunicativos e níveis de formalidade. Enfim, o livro didático representa um apoio para o professor, por vezes, o apoio mais acessível, o que implica a demanda da escola por livros que, de fato, priorizem a ampliação das competências dos alunos na produção e recepção das diferentes práticas das diversas linguagens." (BRASIL, 2009, p. 23)

Como se pode verificar, o livro didático é entendido pelo estudioso francês e pelo Governo Federal como um apoio para o professor e um suporte de valores e conteúdos passíveis de promover a reflexão. No entanto, ele só chega a exercer todas as funções que lhe cabem (ou algumas delas) com a mediação do docente, que o analisa, escolhe e utiliza. Dessa forma, o LD deve ser um meio e não um fim no cenário da Educação. Limitado, incompleto e sem vida, ele só existe pelo uso que se faz dele.

Ao se elaborar uma coleção didática é preciso ter em conta todas essas variantes e abarcar, na medida do possível, as necessidades de públicos diversos. Ademais, é necessário lidar com as limitações de toda ordem mencionadas por Choppin (2001, p. 214215), sem perder de vista o objetivo maior de contribuir para a Educação.

\section{O LIVRO DIDÁTICO PARA O PNLD}

Esclarecido o que é e o que se pode (ou não) esperar de um livro didático destinado ao PNLD (mas não exclusivamente), trataremos de elencar e fazer algumas considerações referentes a três aspectos que subjazem à edição de tais materiais - a saber: especificações, inovação e impacto do PNLD de LEM para os envolvidos e afetados pelo programa.

\section{Especificações}

Visando estabelecer objetivos e critérios para a análise dos materiais didáticos inscritos no PNLD, o MEC, por meio da Secretaria de Educação Básica (SEB) e do Fundo Nacional de Desenvolvimento da Educação (FNDE), publica o edital de convocação para a inscrição de avaliação e seleção de obras didáticas. 
Como vimos, uma das funções do LD é ser o suporte dos valores que uma sociedade deseja transmitir à sua juventude e dos conteúdos programáticos das diversas disciplinas. Nesse sentido, os editais determinam que seja respeitada a legislação, as normas e diretrizes nacionais vigentes referentes à Educação e aos diversos aspectos da vida social ${ }^{5}$. Segundo Costa (2014, p. 43-44):

os editais do PNLD delineiam um livro didático (LD) ideal, sustentado em determinadas perspectivas teórico-metodológicas assumidas em documentos tais como Parâmetros Curriculares Nacionais (BRASIL/SEF, 1998) e as Orientações Curriculares para o Ensino Médio. (BRASIL/SEB, 2006)

Ademais, de acordo com Vazquez (2014, p. 100): "No caso do Edital de convocação para avaliação dos LDs há grande detalhamento dos itens que normatizam e, dessa forma, uma maior complexidade em relação ao seu conteúdo através de especificidades que geram uma hierarquização de itens". O pesquisador se refere aos critérios eliminatórios comuns a todas as disciplinas e outros específicos por área, que compõem os editais e estabelecem as bases sobre as quais se dará a avaliação.

Desse modo, o Governo Federal determina de quais referenciais partirá para a análise das obras e caberá aos autores e às editoras respeitá-los. Nessa relação comercial de

\footnotetext{
${ }^{5}$ Alguns textos legais, normas e diretrizes variam nos editais em função do nível escolar em questão. A título de exemplo, elencamos as que constam do Edital de Convocação 04/2015 referente ao PNLD 2018: a. Constituição da República Federativa do Brasil. b. Lei de Diretrizes e Bases da Educação Nacional (Lei ${ }^{\circ}$ 9.394/96), com as respectivas alterações introduzidas pelas Leis mencionadas a seguir: b.1. Lei $\mathrm{n}^{\mathrm{o}}$ 10.639/2003 - obrigatoriedade da temática "História e Cultura Afro-Brasileira" b.2. Lei $\mathrm{n}^{\circ}$ 11.645/2008 obrigatoriedade da temática "História e Cultura Afro-Brasileira e Indígena" b.3. Lei n ${ }^{\circ} 11.684 / 2008$ - inclui a Filosofia e a Sociologia como disciplinas obrigatórias nos currículos do ensino médio b.4. Lei $\mathrm{n}^{\mathrm{0}}$ 11.769/2008 - Ensino de Música b.5. Lei no 12.061/2009 - Universalização do Ensino Médio b.6. Lei no 12.287/2010 Ensino de Arte b.7. Lei ${ }^{\circ}$ 13.006/2014 - obriga a exibição de filmes de produção nacional nas escolas de educação básica b.8. Lei n ${ }^{0}$ 13.010/2014 - Conteúdos relativos aos direitos humanos e à prevenção de todas as formas de violência contra a criança e o adolescente serão incluídos, como temas transversais, nos currículos escolares c. Estatuto da Criança e do Adolescente (Lei $n^{\circ}$ 8.069/1990), com as respectivas alterações. d. Diretrizes Curriculares Nacionais para o Ensino Médio, Resolução no 2, de 30 de janeiro de 2012 e Parecer $\mathrm{CNE} / \mathrm{CEB} n^{\circ}$ 5/2011. e. Diretrizes Curriculares Nacionais Gerais para a Educação Básica, Resolução $n^{\circ} 4$, de 13 de julho de 2010 e Parecer CNE/CEB nº 7/2010. f. Resoluções e Pareceres do Conselho Nacional de Educação, em especial: f.1. Parecer CEB n 15 de 04/07/2000 - Trata da pertinência do uso de imagens comerciais nos livros didáticos. f.2. Parecer CNE/CP $n^{\circ} 3,10 / 03 / 2004$ e Resolução CNE/CP $n^{\circ} 01$ de 17/06/2004 - Aborda assunto relativo às Diretrizes Curriculares Nacionais para a Educação das Relações Étnico - Raciais e para o Ensino de História e Cultura Afro - Brasileira e Africana. f.3. Parecer CNE/CP No 14 de 06/06/2012 e Resolução CNE/CP no 2, 15/07/2012 - Estabelece as Diretrizes Curriculares Nacionais para a Educação Ambiental (DCNEA). (Disponível em <http://www.fnde.gov.br/programas/livro-didatico/livrodidatico-editais/item/7932-pnld-2018>. Acesso em: 7 jun. 2016).
} 
um lado está o cliente, que oferece especificações extensivas para o material, e do outro estão os fornecedores que tentam atender a tal solicitação. Para tanto, as editoras contam com equipes multidisciplinares de editores de conteúdo, de arte e digital (em geral, especializados na disciplina em questão) e firmam parcerias com autores para, juntos, interpretarem e viabilizarem o edital, transformando-o em um produto adequado para os afetados: professores, alunos e sociedade.

Outro ponto importante relacionado ao programa em discussão e sobre o qual cabem algumas reflexões, são os prazos. Os editais para a análise e compra de materiais são dados a conhecer, em média, três anos antes da utilização dos livros. Sendo assim, o edital para o PNLD 2011 foi publicado em 2008; a entrega dos modelos para análise foi feita em 2009; a divulgação do Guia com a indicação dos livros aprovados, a escolha pelas escolas e a compra aconteceram em 2010; e a efetiva utilização se deu em 2011. O processo ocorreu em períodos equivalentes nos demais editais. No entanto, do ponto de vista editorial, entre a publicação do edital e a entrega dos modelos para avaliação há um lapso de quatro meses, o que leva os autores e as editoras a começarem a elaborar suas obras antes mesmo de terem acesso ao teor das determinações oficiais. Se bem é verdade que a maioria dos critérios se repete a cada edição do programa, alguns vêm sendo modificados ao longo dos anos e somente quando o edital é divulgado é que se tem conhecimento das alterações, restando, como mencionado, apenas quatro meses para ajustes, impressão, checagem gráfica e entrega.

Segundo informações do setor editorial com relação ao número de obras inscritas reprovadas em todas as edições, ter uma lista de critérios não é receita de aprovação para a elaboração de uma obra; não é tarefa fácil a transposição das orientações aos autores e editores para um livro adequado e acessível a professores e alunos de todo o país.

Há de se considerar também que não existe garantia de que, uma vez aprovadas, tais coleções sejam os melhores materiais disponíveis para os professores dado o longo período entre a elaboração e a utilização em sala (aproximadamente três anos) e a ausência de dinamicidade intrínseca ao LD impresso.

Sob a regência de diversos fatores, a edição de LDs para o PNLD transita entre o possível e o desejável: 
A economia da edição escolar possui características específicas que dependem das diversas pressões que são exercidas sobre elas, em maior ou menor medida dependendo da época. Valeria a pena realizar estudos mais profundos nesse campo.

Vimos que os produtos da edição clássica estão sujeitos a uma regulamentação mais restrita que aquela aplicada às demais produções do espírito. Contudo, os editores escolares também estão submetidos às pressões de outra(s) natureza(s): são de caráter pedagógico, como o atendimento aos programas e às instruções oficiais; são também de caráter financeiro, pois o início de um livro didático requer um investimento prévio comparativamente mais significativo do que o de outros produtos editoriais [.... . ${ }^{6}$ (Tradução livre nossa.) (CHOPPIN, 2001, p. 222)

Assim, tendo em consideração todas as variáveis citadas (ou apesar delas), a edição de materiais voltados aos programas nacionais se dá de forma financeira e didaticamente responsável e desafiadora.

\section{Inovação}

A inserção de LEM no PNLD foi, certamente, a maior inovação no cenário editorial de inglês e espanhol na última década: promoveu o crescimento significativo do setor em volume de vendas e instigou os profissionais a buscarem novas especializações.

Tal novidade causou impactos no cronograma das editoras, que até então lidavam com prazos conhecidos e controlados de produção, divulgação e entrega de livros para o mercado privado.

Vale salientar que esse LD destinado ao PNLD não tinha precedentes na produção nacional (muito menos na internacional) por propor um material inovador do ponto de vista teórico-metodológico. Diferentemente das abordagens estrutural, comunicativa ou por tarefas, que vinham à frente do cenário de ensino de línguas no país e no mundo, o MEC,

\footnotetext{
${ }^{6}$ Texto original: La economía de la edición escolar posee características especificas que dependen de las numerosas presiones que sobre ellas se ejercen, con mayor o menor medida según las épocas. Merecería la pena que se realizaran estudios más profundos en ese campo.

Hemos visto que los productos de la edición clásica están sujetos a una reglamentación más estricta que la que se aplica a las demás producciones del espiritu. Pero los editores escolares también están sometidos a las presiones de otra(s) naturaleza(s): son de orden pedagógico, como la conformidad con los programas y las instrucciones oficiales; son también de orden financiero, puesto que la puesta en marcha de un libro de clase requiere una inversión previa más importante comparativamente que otros productos editoriales [...].
} 
por meio do edital, apresentou uma proposta diretamente relacionada à interação social, para a qual é preciso preparar o aluno para atuar de forma crítica e reflexiva na sociedade.

Se bem é verdade que tal prerrogativa já constava dos documentos oficias que regem a Educação nacional, foi necessário retornar a eles e, de fato, segui-los, para romper com a tradição historicamente consolidada de se ensinar línguas com propósitos mais conteudistas.

Assim, a inovação se concretizou no âmbito da edição de LDs. Do ponto de vista do negócio, o novo cliente expandiu as possibilidades de vendas, promoveu novos cronogramas e tipos de investimento e motivou uma formação mais direcionada do setor. Do ponto de vista didático, trouxe à luz uma vertente teórico-metodológica alinhada aos valores que a sociedade atual reconhece como necessários à formação de suas crianças e adolescentes, contemplando, desta forma, novas leituras dos aspectos político, programático e pedagógico propostos por Choppin (2001, p. 214-215).

\section{O impacto do PNLD de LEM}

Para além de números e cifras, é fundamental questionar qual é a medida do sucesso do programa - e, consequentemente, da edição de materiais a ele dirigidos - para os seus envolvidos e afetados, a saber: governo, sociedade, professor, aluno, profissionais do livro, editoras.

Do ponto de vista do Estado e, portanto, das esferas governamentais relacionadas à Educação, é inegável o ganho de alcance e qualidade obtido com a seleção e distribuição de LDs de línguas estrangeiras modernas para todo o país. Disciplinas até então pouco reconhecidas e valorizadas passaram a ocupar um espaço na grade horária das escolas e a presença de tal recurso criteriosamente selecionado tem contribuído para a formação de uma sociedade mais crítica e preparada para as relações socioculturais.

Quanto aos professores, poder contar com um recurso adequado, legitimado e custeado pelo Estado contribuiu para o seu reconhecimento. Ademais, proporcionou aulas mais ricas e produtivas, dado que as propostas de trabalho não precisam ser copiadas do quadro. Nesse sentido, os alunos também foram beneficiados com materiais com qualidade didática e visual, motivando sua aprendizagem. No entanto, se por um lado os docentes foram empoderados com meios e autonomia para desenvolver sua prática, a ausência de 
esclarecimentos e orientações para nortear a sua escolha pode levar ao mau uso (ou até ao abandono) dessa ferramenta.

Ainda sobre os alunos - principais beneficiados pelo programa - e sua relação com o LD, Freitag, Motta e Costa (1993, p. 90) afirmam que é impossível

determinar qual exatamente a responsabilidade do livro didático na formação ideológica, pois [...] parece ignorar que durante esse mesmo período a criança estava sendo simultaneamente ideologizada por possíveis aulas de catecismo, pelas novelas de rádio e televisão, por revistas em quadrinhos, pelos próprios pais e parentes e assim por diante.

Contudo, se não é possível estabelecer critérios quantitativos para determinar o impacto do LD na aprendizagem discente, é factível afirmar que o uso de tal recurso compõe a formação escolar e social de tais jovens, para além dos conteúdos linguísticos.

Para os profissionais do livro (incluídos, aqui, os autores) e as editoras de materiais de LEM, como comentamos, o programa significou uma reinvenção: ampliou do mercado de trabalho, contribuiu para a especialização dos envolvidos e proporcionou a oportunidade de produzir um material inovador.

\section{CONSIDERAÇÕES FINAIS}

É evidente que, apesar de reconhecermos as mudanças e os avanços trazidos pelo advento do PNLD de LEM, ainda há muito a ser feito e questionado. Estão de fato os LDs de acordo com as expectativas do Governo, da sociedade, dos docentes e dos alunos, dada a diversidade de um país heterogêneo como o Brasil? O que é preciso ser revisto para tornar o processo de edição de LDs mais assertivo e eficaz?

No mesmo sentido desses questionamentos, afirma Costa (2014, p. 45):

[...] cabe observar que o LD tem de atender a diferentes demandas, de acordo com realidades muito diversas. O Brasil é um país de dimensões continentais, com escolas em contextos urbanos (centro e periferia) e rurais (alguns mais, outros menos afastados das cidades), em regiões com aspectos geográficos, sociais e culturais muito diferentes entre si. Além disso, um mesmo livro pode agradar mais a um professor do que a outro, porque os profissionais têm perfis diferenciados, se sentem mais à vontade com determinada abordagem metodológica, têm preferências quanto a formas de desenvolver os conteúdos e as habilidades e nem sempre se adaptam às outras. Tendo em vista essa diversidade, pode-se concluir que 
é praticamente impossível que um mesmo livro possa adequar-se perfeitamente a cada situação.

Não há LD perfeito nem universal, mas essa constatação não inviabiliza nem que se procure preparar livros tendo em mente a heterogeneidade das escolas, professores e ex-alunos, e nem que se estabeleçam alguns parâmetros para a produção de livros que, uma vez selecionados, serão disponibilizados para as escolas de todo o país.

Do ponto de vista da edição, podemos atestar que é incansável a busca pela elaboração de materiais adequados ao programa e, consequentemente, ao ensino e aprendizagem de LEMs. Entendemos que nossa contribuição à Educação nacional, embora periférica ao fazer docente, ocupa lugar relevante no dia a dia da sala de aula e aceitamos tal desafio com responsabilidade e comprometimento.

\section{REFERENCIAS}

BRASIL. MEC/FNDE/SEB. Edital de convocação para inscrição no processo de avaliação e seleção de obras didáticas para o programa nacional do livro didático PNLD 2012 - Ensino Médio. Disponível em: <http://www.fnde.gov.br/programas/livrodidatico/guias-do-pnld/item/2988-guia-pnld-2012-ensino-m\%C3\%A9dio $>$. Acesso em: 8 jun. 2016.

BRASIL. MEC/FNDE/SEB. Edital de convocação para o processo de inscrição e avaliação e seleção de obras didáticas para o programa nacional do livro didático PNLD 2018. Disponível em: <http://www.fnde.gov.br/programas/livro-didatico/livrodidatico-editais/item/7932-pnld-2018>. Acesso em: 7 jun. 2016.

CHOPPIN, A. Pasado y presente de los manuales escolares. Traduzido por Miriam Soto Lucas. Revista Educación y Pedagogía. Medellín: Facultad de Educación. Vol. XIII, no 2930, enero-septiembre, 2001, p. 209-229.

COSTA, E. G. M. Que livro didático nós queremos? Reflexões a partir do PNLD de língua estrangeira. In: CORDEIRO, A. L. et al (orgs.). Hispanismo no Brasil. Reflexões e sentidos em construção. São Carlos: Pedro e João Editores, 2014, p. 43-82.

FREITAG, B.; MOTTA, V.; COSTA, W. O livro didático em questão. São Paulo: Cortez, 1993.

MUNAKATA, K. Produzindo livros didáticos e paradidáticos. 223 f. Tese de doutorado Pontifícia Universidade Católica de São Paulo, São Paulo, 1997. 
TEIXEIRA, A. L. S. Autoria no livro didático de língua portuguesa: o papel do editor. 219 f. Dissertação de mestrado - Universidade Estadual de Campinas, Campinas, 2012.

VAZQUEZ, R. P. PNLD 2011 de Língua Estrangeira: sentidos de docência, ensino e língua. 176 f. Tese de doutorado - Universidade Federal do Rio de Janeiro, Rio de Janeiro, 2014.

\section{AS AUTORAS}

\section{Roberta Amendola}

Possui bacharelado e licenciatura em Letras Português-Espanhol pela USP, pósgraduação lato sensu em Ensino de Espanhol para Brasileiros pela PUC-SP e Aperfeiçoamento para Executivos do Mercado Editorial pela FIA-USP/CBL. É autora e editora de obras didáticas e paradidáticas de espanhol como língua estrangeira (E/LE). Atualmente cursa o Mestrado em Educação na USP e é gerente editorial de E/LE do departamento de idiomas do Grupo Santillana no Brasil. É membro do Grupo de Pesquisa Ensino e aprendizagem de espanhol, certificado pelo CNPq/USP, e do grupo de estudos sobre criatividade na prática educacional, o The C Group, da Inglaterra.

Email: roberta.amendola@usp.br

\section{Sandra Possas}

Possui bacharelado e licenciatura em Letras - Inglês pela Universidade Católica de Petrópolis e MBA em Gestão de Negócios pelo Ibmec/RJ. É Mestre em Educação pelo Instituto de Educação da Universidade de Londres. Atualmente é diretora editorial do departamento de idiomas do Grupo Santillana no Brasil.

Email: spossas@richmond.com.br 